See Article page 1769.

\section{Commentary: Are serious adverse events inevitable?}

\author{
Rizwan A. Manji, MD, PhD, FRCSC, MBA, a,b and \\ Rakesh C. Arora, MD, PhD, FRCSC ${ }^{a, b}$
}

In this issue of the Journal, Lala and colleagues ${ }^{1}$ show that $30 \%$ of patients undergoing cardiac surgery (CS) for ischemic mitral regurgitation will not be able to go home at discharge. These patients not discharged to home have more than a 4-fold risk of death and 1.5 times risk of new serious adverse events (SAEs) over the next year. The authors state that preoperative factors of age, diabetes mellitus, heart failure (HF), and postoperative SAEs are important risk factors for not being discharged to home.

As the authors state, this information is important for decision making and guiding expectations after CS; however, it does not address the fact that SAEs during the postoperative hospital stay may be preventable. Surgeons can try and optimize preoperative variables (eg, diabetes mellitus, $\mathrm{HF}$ ), but their influence is more on postoperative events. Adverse events occur in $12 \%$ of patients undergoing $\mathrm{CS}$, and more than $50 \%$ are potentially preventable. $^{2}$ Hospital-acquired infections are a common reason for adverse events after $\mathrm{CS}^{3}$ and was the most common SAE influencing not being discharged to home in the article by Lala and colleagues (odds ratio, $7.42 ; 95 \%$ confidence interval, 2.31-30.77).

Could a delay in recognizing infection lead to preventable SAE? It is known that one of the most common diagnoses missed in hospitalized patients is infection (often pneumonia and sepsis). ${ }^{4,5}$ The reason that infection may be missed is that older definitions (systemic inflammatory

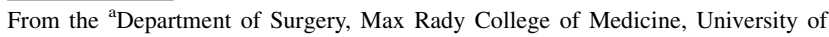
Manitoba, Winnipeg, Manitoba, Canada; and ${ }^{\mathrm{b}}$ Cardiac Sciences Program, St Boniface Hospital, Winnipeg, Manitoba, Canada.

Disclosures: Dr Arora has received an unrestricted educational grant from Pfizer Canada Inc. and honoraria from Mallinckrodt Pharmaceuticals and Edwards Lifesciences for work unrelated to this work. Dr Manji has nothing to disclose with regard to commercial support.

Received for publication March 4, 2020; revisions received March 4, 2020; accepted for publication March 5, 2020; available ahead of print March 20, 2020.

Address for reprints: Rizwan A. Manji, MD, PhD, FRCSC, MBA, I.H. Asper Clinical Research Institute, St Boniface Hospital, CR 3014 - 369 Tache Ave, Winnipeg, Manitoba, R2H 2A6 Canada (E-mail: rmanji@sbgh.mb.ca).

J Thorac Cardiovasc Surg 2021;162:1779-80

$0022-5223 / \$ 36.00$

Copyright (c) 2020 by The American Association for Thoracic Surgery

http://dx.doi.org/10.1016/j.jtcvs.2020.03.036
}

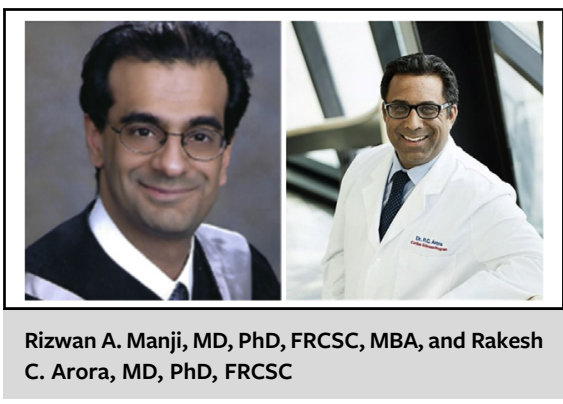

CENTRAL MESSAGE

Serious adverse events (eg, infection) may be preventable if we are aware of the most recent evidence and are vigilant.

response syndrome) that rely on temperature and white blood cell count to diagnose infection are often solely used to make the diagnosis. In addition, there may be excessive dependence on positive culture results to diagnose infection. However, there are newer criteria to diagnose infection. Thirty-one societies have endorsed the Third International Consensus Definitions for Sepsis and Septic Shock (Sepsis-3), which states that systemic inflammatory response syndrome has inadequate specificity and sensitivity to diagnose infection and that the Sequential Organ Failure Assessment (SOFA) score should be used instead. ${ }^{6}$ Sepsis-3 suggests using SOFA to look at end organ dysfunction in a patient with suspected infection to quickly start investigations and treatment. ${ }^{6}$ Sepsis 3 also suggests that infection may be occult, and the phenotype of sepsis can be altered in a patient by multiple factors; therefore, one should think of infection in any patient presenting with organ dysfunction and be vigilant in looking for infection. ${ }^{6}$ In addition, there is literature noting that good-quality sputum samples are obtained in only $14.4 \%$ of patients, ${ }^{7}$ and cultures in septic patients are negative in $29 \%{ }^{8}$ to $68 \%{ }^{9}$ of cases; thus, one cannot solely rely on getting a positive culture to diagnose infection.

We must resist thinking that SAE after CS, such as infection, is inevitable. Using updated evidence (SOFA instead of systemic inflammatory response syndrome) and realizing the error present in culture results may allow earlier detection of infection allowing prompt treatment to avoid getting an SAE. Research endeavors to increase awareness of newer evidence and being vigilant to avoid 
SAE needs to be done. Prevention is key to getting patients home.

\section{References}

1. Lala A, Chang HL, Liu X, Charles EJ, Yerokun BA, Bowdish ME, et al. Risk of non-home discharge following surgery for ischemic mitral valve disease. J Thorac Cardiovasc Surg. 2021;162:1769-78.e7

2. Wahr JA, Abernathy JH. Improving patient safety in the cardiac operating room: doing the right thing the right way, every time. Curr Anesthesiol Rep. 2014;4: 113-23.

3. Nilsson L, Risberg MB, Montgomery A, Sjödahl R, Schildmeijer K, Rutberg H. Preventable adverse events in surgical care in Sweden - a nationwide review of patient notes. Medicine. 2016;95:e3047.

4. Tudela P, Carreres A, Ballester M. Diagnostic errors in emergency departments. Med Clin. 2017;149:170-5.
5. Newman-Toker DE, Schaffer AC, Yu-Moe CW, Nassery N, Saber Tehrani AS, Clemens GD, et al. Serious misdiagnoses-related harms in malpractice claims: the "big three" - vascular events, infections, and cancers. Diagnosis (Berl). 2019;6:227-40.

6. Singer M, Deutschman CS, Seymour CW, Shankar-Hari M, Annane D, Bauer M, et al. The third international consensus definitions for sepsis and septic shock (Sepsis-3). JAMA. 2016;315:801-10

7. Garcia-Vazquez E, Marcos MA, Mensa J, de Roux A, Puig J, Font C, et al. Assessment of the usefulness of sputum culture for diagnosis of community-acquired pneumonia using the PORT predictive scoring system. Arch Intern Med. 2004;164:1807-11.

8. Kumar A, Ellis P, Arabi Y, Roberts D, Light B, Parrillo JE, et al. Initiation of inappropriate antimicrobial therapy results in a fivefold reduction of survival in human septic shock. Chest. 2009;136:1237-48.

9. Bernard GR, Ely EW, Wright TJ, Fraiz J, Stasek JE Jr, Russell JA, et al. Safety and dose relationship of recombinant human activated protein $\mathrm{C}$ for coagulopathy in severe sepsis. Crit Care Med. 2001;29:2051-9.
See Article page 1769.

\section{Commentary: Ptolemy versus Copernicus: The times they are a-changin'}

\author{
James R. Edgerton, MD, FACC, FACS, FHRS
}

In this issue of the Journal, Lala and colleagues ${ }^{1}$ report a secondary analysis of 552 patients discharged alive after surgery for moderate or severe mitral insufficiency. Patients were followed at least a year and analyzed for risk factors for non-home discharge (NHD) and associated outcomes including death, serious adverse events (SAEs), and quality of life (QOL). The risk factors for NHD included older age (odds ratio [OR], 1.52), history of diabetes (OR, 1.94), and previous heart failure (OR, 1.64). Postoperative SAEs almost doubled the risk of NHD. Comparing patients discharged to home versus NHD, at 1 year the hazard ratio for death among the NHD was an impressive 4.29. Curiously, there was no difference in QOL.

From the Baylor, Scott, \& White Health, Dallas, Tex; and Department of Biology, College of Charleston, Charleston, SC.

Disclosures: Author has nothing to disclose with regard to commercial support.

Received for publication March 17, 2020; revisions received March 17, 2020; accepted for publication March 18, 2020; available ahead of print April 6, 2020.

Address for reprints: James R. Edgerton, MD, FACC, FACS, FHRS, Baylor, Scott, \& White Health, Dallas, TX 75246-2017 (E-mail: JamesEdgertonMD@gmail.com). J Thorac Cardiovasc Surg 2021;162:1780-1

$0022-5223 / \$ 36.00$

Copyright $($ c 2020 by The American Association for Thoracic Surgery

http://dx.doi.org/10.1016/j.jtcvs.2020.03.102

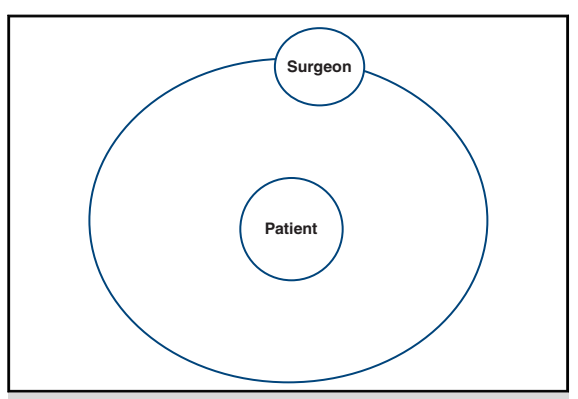

Putting patients' concerns at the center of data reporting requires a shift in practice.

CENTRAL MESSAGE

As we move to patient-centered medicine, outcomes we track must be those meaningful to patients and their families. To do this, we must transition from proceduralists to practicing disease management. 